\title{
Chemical stability of innovative grouts for cast basalt elements
}

\author{
T Zlebek ${ }^{1}$, J Hodul ${ }^{1}$, L Meszarosova ${ }^{1}$ and R Drochytka ${ }^{1}$ \\ ${ }^{1}$ Department of Building Materials and Components, Faculty of Civil Engineering, \\ Brno University of Technology, Veveri 331/95, Brno 602 00, Czech Republic
}

Email: zlebek.t@fce.vutbr.cz

\begin{abstract}
Newly developed tile grouts are intended mainly for environment with strong chemical loading. For this reason, chemical resistance was one of the key parameters observed. The grout for cast basalt tile was polymer based, in particular with epoxide binder and it utilized solidified hazardous wastes as fillers. It is well-known that epoxide binder has high resistance to solutions of inorganic substances. However, it is easily degraded by organic compounds. This was taken into consideration when assessed aggressive environments and their concentrations were selected. Examined substances were $60 \%$ solution of sulfuric acid, vapors of this acid (at concentration 96\%) and 10\% solution of acetic acid. After exposition to action of these aggressive substances, first of all the visual changes were assessed, i.e. change of color, formation of blisters, cracks, flaking or change of sheen. Then influence on microstructure, changes of bulk density and strengths of materials were observed.
\end{abstract}

\section{Introduction}

In the building industry there are many possibilities, how to prepare tile grouts. Usually are grouts prepared with inorganic cement binder [1]. There is possibility to use polymers in the process in preparation of grouts. Epoxy resins are one of the widely used resins to produce polymer- modified concretes and mortars [2]. Epoxy grouts are used in applications with required high strength, rapid setting, handling versatility dynamic, load bearing, critical alignment and resistance against aggressive chemical environment $[3,4,5]$. It is well-known that epoxide binder has high resistance to solutions of inorganic substances. However, it is easily degraded by organic compounds. Tile grouts should have maximal adhesion to the base and high tensile and shear strength, rather than other mechanical properties [6]. For very good properties of epoxy resins, it is necessary to pay quite high price. To mitigate the high cost of epoxy resins, a range of fillers can be added to dilute the resin content [7]. For example, very fine graded fillers can be applied into polymer concrete - most of all milled stone materials (for example quartz dust, silica fume, granite meal) [8]. With growing importance of sustainable development requirements is necessary to use wastes and by-products to save raw materials. Fly ash is one of the commonly used filler in epoxy-based polymer concrete [8].

\section{Materials and Methods}

The input materials are fillers in the form solidification product (SP) and the epoxy resin as polymeric binder. The first one of fillers (SP1) consists of the quartz dust (50\%), the fly ash form hightemperature combustion (40\%) and the end product as the hazardous waste from the municipal solid waste incineration, the other one (SP2) consists of the quartz dust (50\%), the fly ash form hightemperature combustion $(40 \%)$ and the hazardous waste in form of cement bypass dust from 
the cement plant. These solidification products were incorporated into the epoxy grouts, and subsequently observed in chemically aggressive environment and compared with reference filler consisted from quartz dust. The standard EN 12808-1 [9] does not give exact definition of limit values for tile grouts chemical resistance, nor chemical substance to be used for resistance tests. However, substance to which the chemically resistant grouts are usually exposed, should be used as testing agent. Similarly, the test conditions (like temperature or humidity) should be close to design conditions, where tested grouts will be applied (sewers and industrial plants with chemical aggressive environment).

Selected chemically aggressive environments and test conditions to which the samples of tile grouts will be exposed:

- $96 \%$ sulfuric acid $\left(\mathrm{H}_{2} \mathrm{SO}_{4}\right)$ p. a.: above surface of $\mathrm{H}_{2} \mathrm{SO}_{4}$ (in vapors), at temperature $60^{\circ} \mathrm{C}$,

- $60 \%$ solution of $\mathrm{H}_{2} \mathrm{SO}_{4}$ : submersion to solution of $\mathrm{H}_{2} \mathrm{SO}_{4}$ at $23^{\circ} \mathrm{C}$,

- $10 \%$ solution of acetic acid $\left(\mathrm{CH}_{3} \mathrm{COOH}\right)$ : submersion to solution at $23^{\circ} \mathrm{C}$.

\section{Results and discussion}

Samples made from the tile grout were measured and weighed before test of chemical resistance. Samples for exposition in vapors of $\mathrm{H}_{2} \mathrm{SO}_{4}$ were then placed on ceramic grid above surface of $96 \%$ $\mathrm{H}_{2} \mathrm{SO}_{4}$. Glass vessel with samples and chemical agent was the closed and placed for 14 days in drying room, where the temperature was kept constantly at $60^{\circ} \mathrm{C}$. Samples for exposition to $60 \%$ solution of $\mathrm{H}_{2} \mathrm{SO}_{4}$ and in $10 \%$ solution of $\mathrm{CH}_{3} \mathrm{COOH}$, were placed on the bottom of desiccator figure 1 . Individual chemical agents were added in the vessels figure 2; the vessels were closed and stored for 14 days at $23^{\circ} \mathrm{C}$.

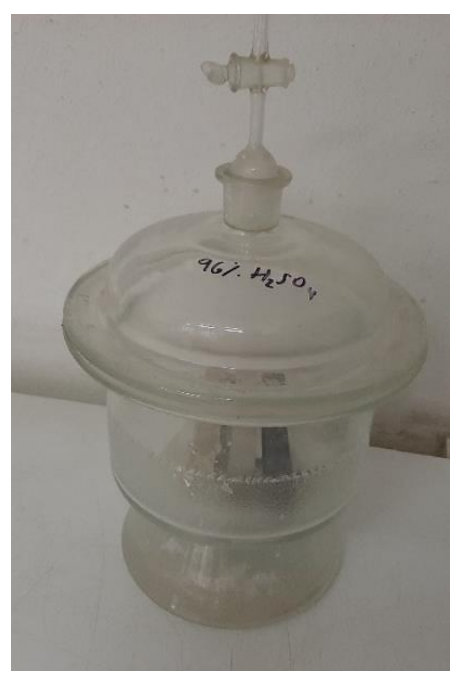

(a)

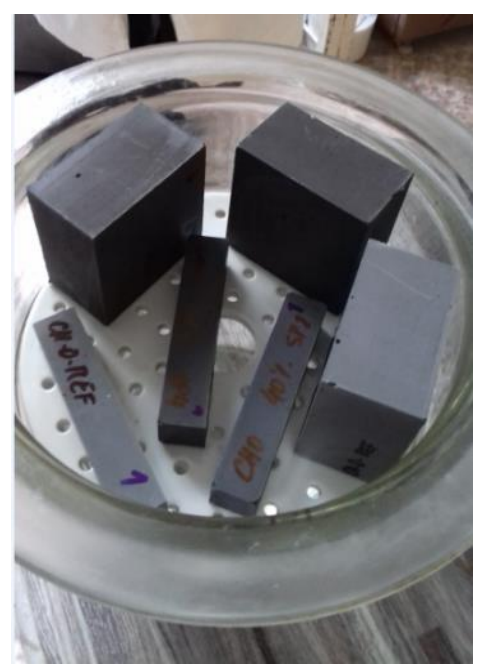

(b)

Figure 1. Location above surface of $\mathrm{H}_{2} \mathrm{SO}_{4}$ (in vapors); samples placed in the glass desiccator (a), on ceramic grid above surface of $96 \% \mathrm{H}_{2} \mathrm{SO}_{4}(\mathrm{~b})$. 


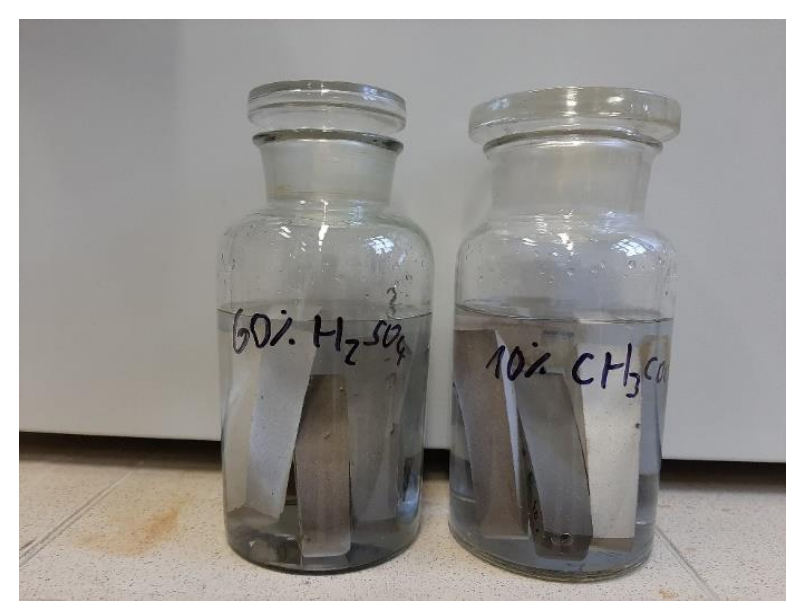

Figure 2. Testing samples placed in $60 \%$ solution of $\mathrm{H}_{2} \mathrm{SO}_{4}$ and $10 \%$ solution of $\mathrm{CH}_{3} \mathrm{COOH}$.

Selection of chemical agents and testing environments were maximally chosen close to conditions determined by environment, where the materials will be applied in practice - the grout utilization is intended for chemical aggressive environment with very low $\mathrm{pH}$, up to value of 1 , what represents very acid aggressive environment.

After selected time of exposition, the samples were taken out of the vessel with individual chemical substances, dried and visually assessed figure 3. It was found out that samples with all used types of fillers (SP1, SP2 and REF) showed no visual changes after exposition to $96 \%$ vapors of sulfuric acid at the temperature $60^{\circ} \mathrm{C}$. Direct contact of solution of sulfuric acid with the sample caused color changes on the surface, which could be characterized as lighter color shade. Considerable color changes were observed on the samples containing the fillers SP1 and SP2 exposed to solution of acetic acid. Influence of this acid made the color shade lighter and many stains were formed, probably by the precipitation of salts on the surface. Less marked color and visual degradation was observed on the sample containing the filler SP1, which seems to be more suitable from the chemical resistance point of view.

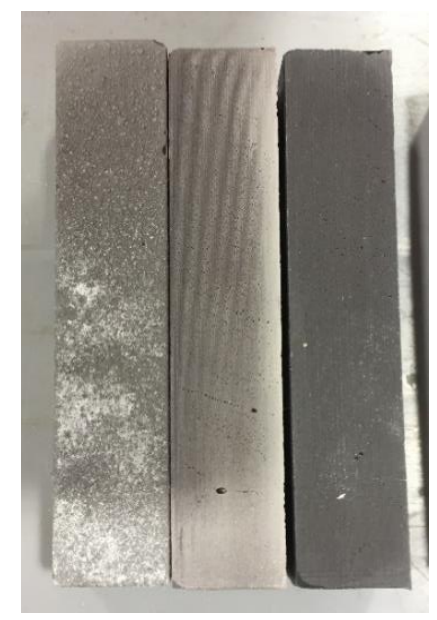

(a)

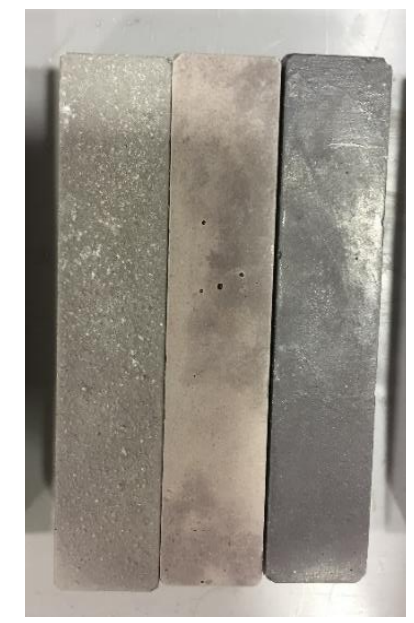

(b)

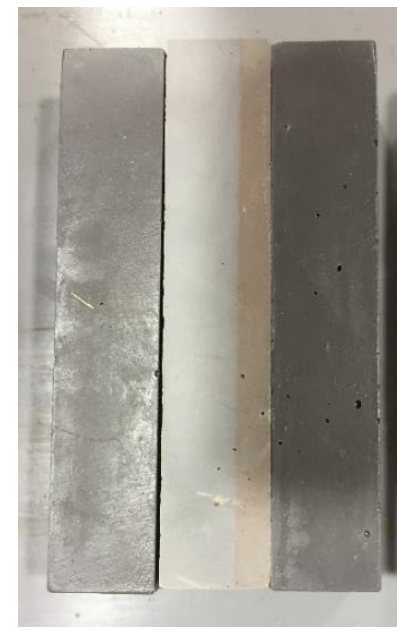

(c)

Figure 3. Samples after the chemical resistance test: left side - reference samples, in the middle samples with the filler SP2, right side - samples with the filler SP1; (a) samples exposed to the $10 \%$ acetic acid solution, (b) samples exposed to $60 \%$ solution of sulfuric acid, (c) samples exposed to the vapors of the $96 \%$ sulfuric acid. 
Samples of the tile grout exposed to chemically aggressive environment were subjected to the microstructure observation by the digital optical microscope. Figure 4 shows clearly progress of color change on the surface of the sample; lighter color shade propagated from the surface to the core of the sample, while darker core is visible in original color. Detailed view of degraded surface layer is visible in figure 5. Color change propagating from the edge of the sample to the middle is not so significant on samples exposed to acetic acid (figure 6). Degradation is observed locally, in separated sections, formed probably by precipitated acetates, which is apparent in the detail of degraded surface in figure 7. It was stated by Kalenda and Kalendova [10] that $\mathrm{H}_{2} \mathrm{SO}_{4}$ is strong acid, so it is almost completely dissociated, and its ions are not able to enter the hydrophobic resin so that attack by this acid takes place only in the surface layer. The organic acids, such as $\mathrm{CH}_{3} \mathrm{COOH}$ and $\mathrm{CH}_{3} \mathrm{CH}_{2} \mathrm{COOH}$ are relatively weak acids and much less dissociated - they act as solvents and their reaction with epoxy resin resulting in swelling, and segments of the macromolecularresin chains are separated.

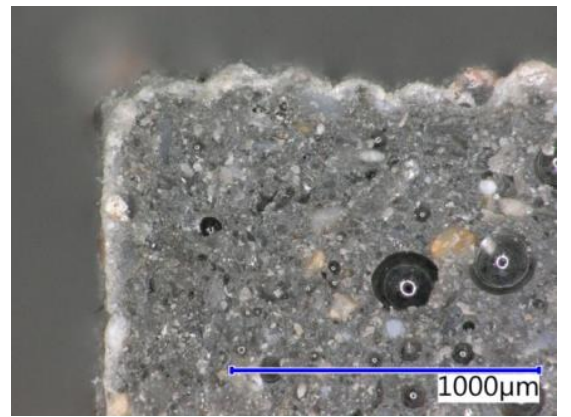

Figure 4. Sample containing the filler SP2 after submersion in the solution of $60 \%$ $\mathrm{H}_{2} \mathrm{SO}_{4}$ - cross section.

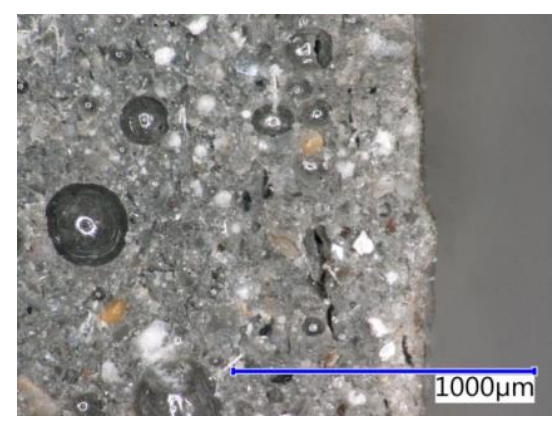

Figure 6. Sample with the filler SP2 after submersion in $10 \% \mathrm{CH}_{3} \mathrm{COOH}-$ cross section.

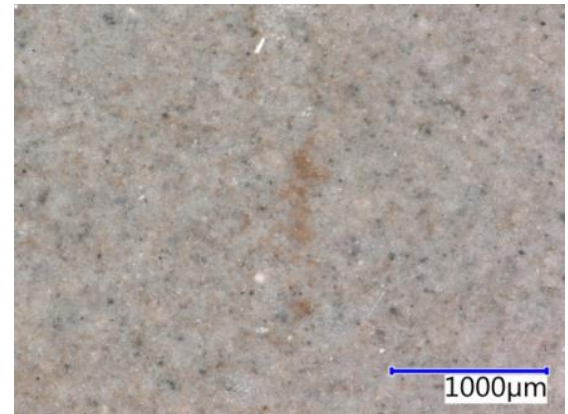

Figure 5. Sample containing the filler SP2 after submersion in the solution of $60 \% \mathrm{H}_{2} \mathrm{SO}_{4}-$ surface.

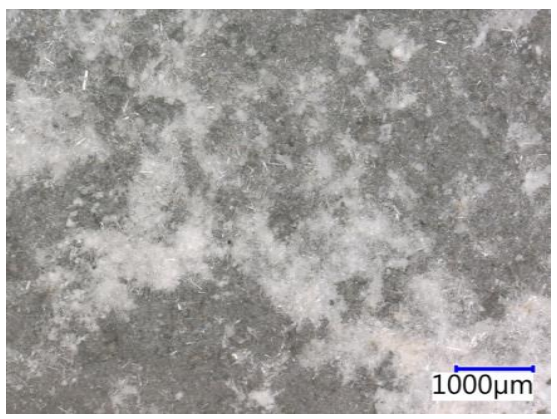

Figure 7. Sample with the filler SP2 after submersion in $10 \% \mathrm{CH}_{3} \mathrm{COOH}$ - surface.

Subsequently, the grout samples were measured and weighed to determine bulk density and for comparison of samples exposed to aggressive environment to those placed only in laboratory conditions. The results of bulk density are summarized in table 1 and figure 8 .

Table 1. Influence of the exposition to aggressive environment to the bulk density of samples.

\begin{tabular}{|c|c|c|c|c|c|c|c|c|c|c|}
\hline \multicolumn{11}{|c|}{ Bulk density $\left[\mathrm{kg} / \mathrm{m}^{3}\right]$} \\
\hline \multicolumn{2}{|c|}{ Laboratory conditions } & \multicolumn{3}{|c|}{$\begin{array}{c}\text { After exposition to } 96 \% \\
\text { solution of sulfuric acid } \\
\text { vapors at } 60^{\circ} \mathrm{C}\end{array}$} & \multicolumn{3}{|c|}{$\begin{array}{l}\text { After submersion in } \\
\text { the solution of } 60 \% \\
\qquad \mathrm{H}_{2} \mathrm{SO}_{4}\end{array}$} & \multicolumn{3}{|c|}{$\begin{array}{l}\text { After submersion in } \\
\text { the solution of } 10 \% \\
\qquad \mathrm{CH}_{3} \mathrm{COOH}\end{array}$} \\
\hline SP1 & REF & SP1 & SP2 & REF & SP1 & SP2 & REF & SP1 & & REF \\
\hline 1370 & 1260 & 1380 & 1370 & 1250 & 1390 & 1390 & 1250 & 1360 & 1360 & 1240 \\
\hline
\end{tabular}




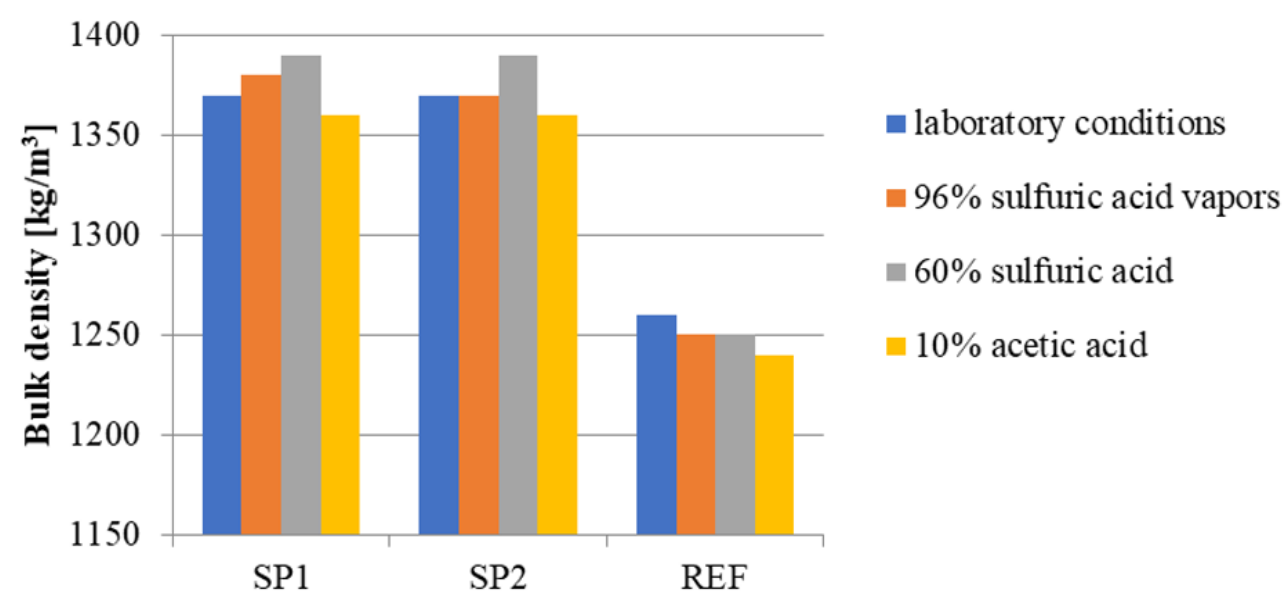

Figure 8. Influence of the exposition to aggressive environment to bulk density change.

The results show the trend of the bulk density reduction of samples with reference filler, caused by action of chemically aggressive environment. Other fillers showed opposite influence and exposure to the sulfuric acid in direct contact with samples caused increase of bulk density; by $10 \%$ in the sample containing SP1 filler. Influence of vapors of this acid caused no changes of bulk density. Action of acetic acid caused reduction of bulk density of all tested materials by approximately 10 to $20 \mathrm{~kg} / \mathrm{m}^{3}$. Hence, it can be stated that selected aggressive environments have no significant influence on change of bulk density.

These samples were then subjected to tests of three-point flexural strength and fragments of the samples were used for the determination of compressive strength. Both tests were performed in accordance with EN 12808-3 European harmonized standard [11]. The results of strengths are summarized in tables 2-3 and in figures 9-10. Properties after exposition to aggressive environment were compared to the reference samples, placed only in laboratory conditions.

Table 2. Influence of the exposition to aggressive environment to flexural strength.

\begin{tabular}{|c|c|c|c|c|c|c|c|c|c|c|c|}
\hline \multicolumn{12}{|c|}{ Flexural strength $\left[\mathrm{N} / \mathrm{mm}^{2}\right]$} \\
\hline \multicolumn{3}{|c|}{$\begin{array}{l}\text { Laboratory } \\
\text { conditions }\end{array}$} & \multicolumn{3}{|c|}{$\begin{array}{c}\text { After exposition to } 96 \% \\
\text { solution of sulfuric acid } \\
\text { vapors at } 60^{\circ} \mathrm{C}\end{array}$} & \multicolumn{3}{|c|}{$\begin{array}{l}\text { After submersion in } \\
\text { the solution of } 60 \% \\
\qquad \mathrm{H}_{2} \mathrm{SO}_{4}\end{array}$} & \multicolumn{3}{|c|}{$\begin{array}{l}\text { After submersion in } \\
\text { the solution of } 10 \% \\
\mathrm{CH}_{3} \mathrm{COOH}\end{array}$} \\
\hline SP1 & SP2 & REF & SP1 & SP2 & REF & SP1 & SP2 & REF & SP1 & SP2 & REF \\
\hline 33.8 & 36.4 & 42.3 & 33.5 & 39.0 & 37.6 & 35.0 & 38.5 & 44.8 & 34.2 & 33.2 & 38.5 \\
\hline
\end{tabular}

Table 3. Influence of the exposition to aggressive environment to compressive strength.

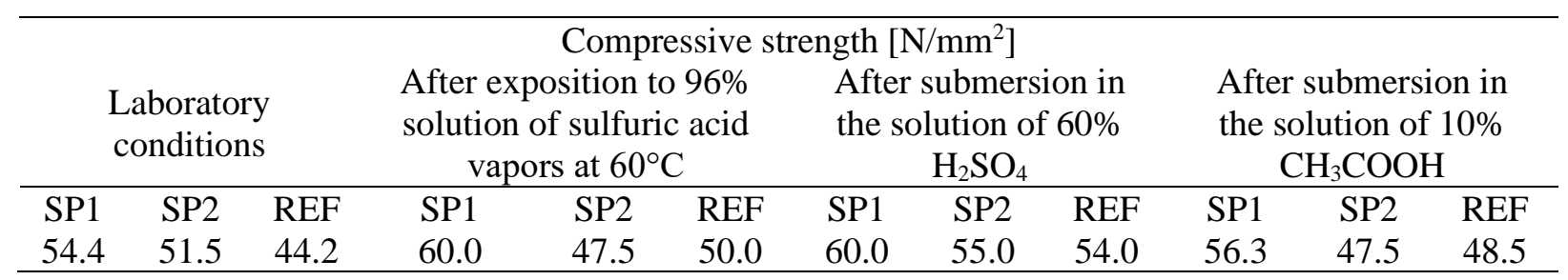




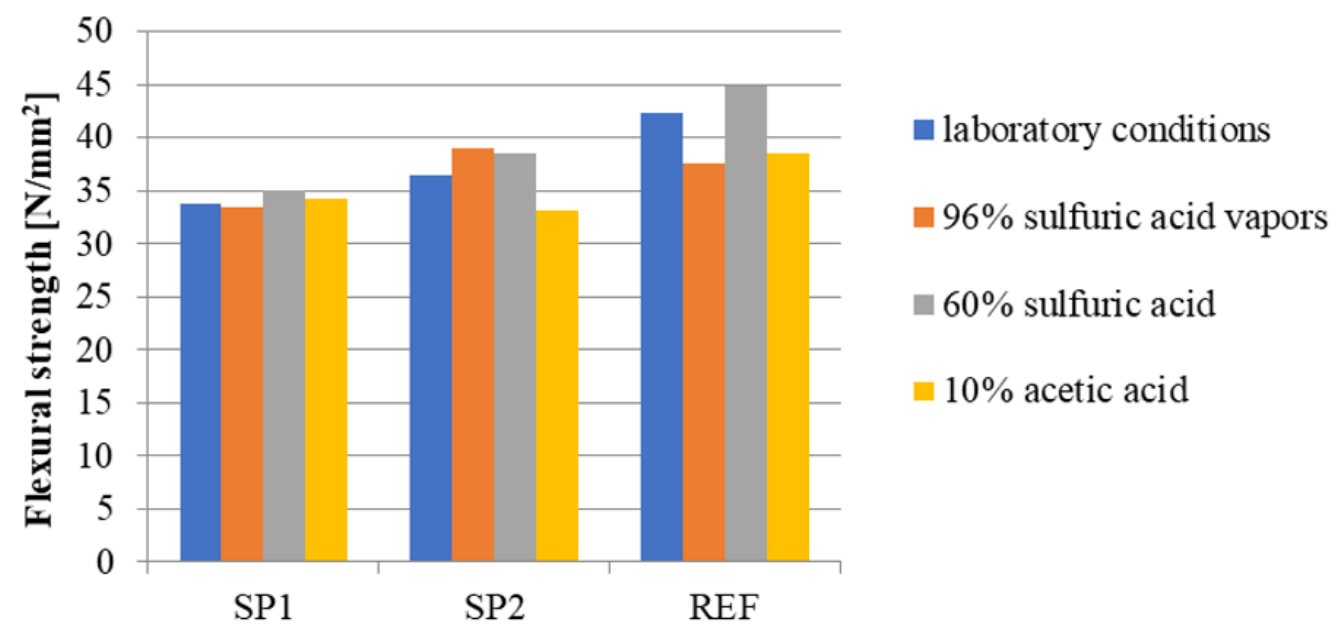

Figure 9. Influence of the exposition to aggressive environment to flexural strength of grout samples.

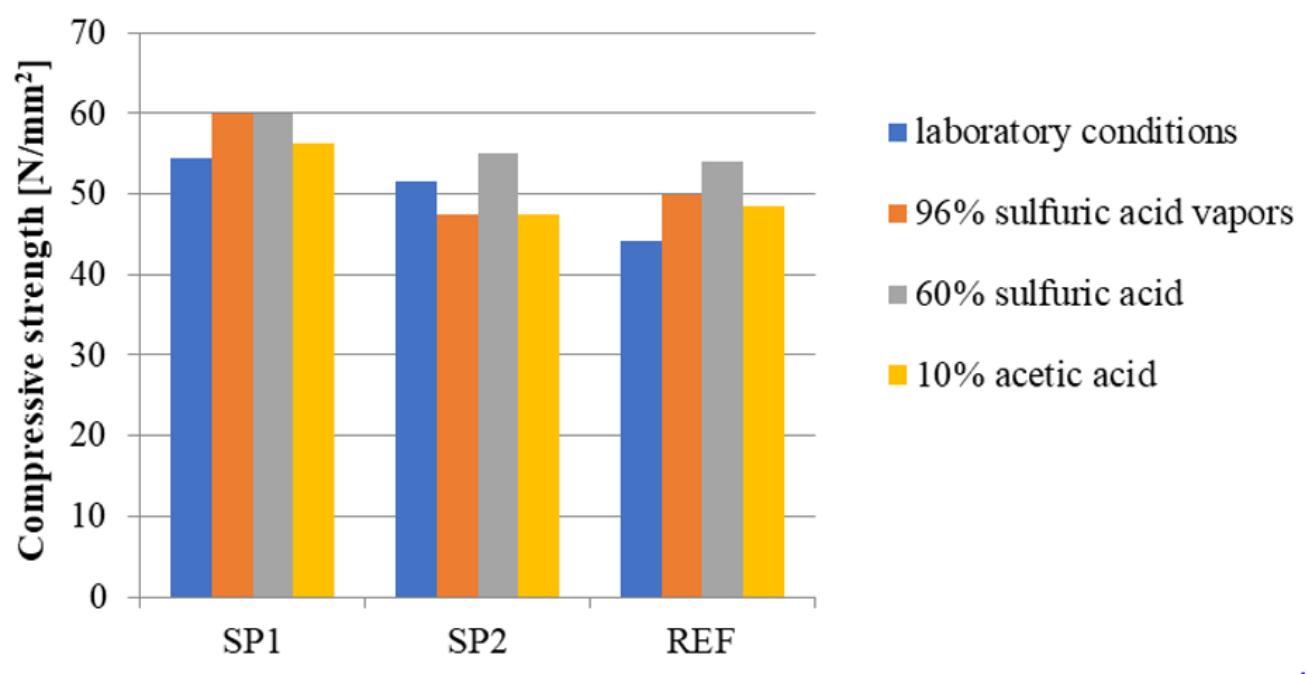

Figure 10. Influence of the exposition to aggressive environment to compressive strength of grout samples.

\section{Conclusion}

The influence of chemical aggressive environment on microstructure, changes of bulk density and strengths of polymeric grout materials were observed and evaluated. The results showed the trend of reduction of bulk density of samples with reference filler, caused by exposure to the chemically aggressive environment. The grouts containing solidification product as the filler showed similar compressive and flexural strength with the reference sample containing only quartz dust as the filler. It is not possible to clearly state the negative influence of exposition of individual samples to various chemical environment based on the results of compressive and flexural strength. The grout with the filler SP1 (the mixture of quartz dust, fly ash and end product) showed quite better strengths than the reference samples. Specimens showed visual changes after exposition to sulfuric acid $(60 \%$ solution) and acetic acid (10\% solution). It can be stated that the use and implementation of specifically prepared fillers (solidification products containing hazardous waste), showed the physical and mechanical properties comparable to the reference material. It could be possible to use such material in defined conditions with aggressive environment, in this case with attack of very low $\mathrm{pH}$, up to the value of $1\left(60 \% \mathrm{H}_{2} \mathrm{SO}_{4}\right)$. 


\section{Acknowledgements}

This paper was supported by the project FAST-S-20-6136 "Study of the incorporation of hazardous waste and secondary raw materials in a polymer matrix of special composite materials".

\section{References}

[1] Palardy D, Onofrei M and Ballivy G 1998 Microstructural changes due to elevated temperature in cement based grouts Advanced Cement Based Materials 8(3-4) pp 132-138

[2] Anagnostopoulos C A, Sapidis G and Papastergiadis E 2016 Fundamental properties of epoxy resin-modified cement grouts Construction and Building Materials 125 pp 184-195

[3] Shamsuddoha M, Islam M M, Aravinthan T, Manalo A and Lau K 2013 Characterisation of mechanical and thermal properties of epoxy grouts for composite repair of steel pipelines Materials \& Design 52 pp 315-327

[4] Kneuer R L and Meyers M 1991 Strengths and limitations of epoxy grouts Concrete international 54 p 6

[5] Prolongo S G, del Rosario G and Ureña A 2006 Comparative study on the adhesive properties of different epoxy resins Int J Adhes Adhes 26 pp 125-32

[6] Luso E and Lourenço P B 2017 Bond strength characterization of commercially available grouts for masonry Construction and Building Materials 144 pp 317-326

[7] Ferdous W, Manalo A, Wong H S, Abousnina R, AlAjarmeh O S, Zhuge Y and Schubel P 2020 Optimal design for epoxy polymer concrete based on mechanical properties and durability aspects Construction and Building Materials 232 pp 117-229

[8] Garbacz A and Sokołowska J J 2013 Concrete-like polymer composites with fly ashes Comparative study. Construction and Building Materials 38 pp 689-699

[9] EN 12808-1:2008 Grouts for tiles. Part 1: Determination of chemical resistance of reaction resin mortars European Committee for Standardization (CEN) (Brussels, Belgium)

[10] Kalenda P and Kalendova A 1994 Improved chemical resistance of epoxy resin-based coating compositions Dyes and Pigments 27(4) pp 305-312

[11] EN 12808-3:2008 Grouts for tiles - Part 3: Determination of flexural and compressive strength European Committee for Standardization (CEN) (Brussels, Belgium) 